\title{
Inertial hybrid algorithm for variational inequality problems in Hilbert spaces
}

\author{
Ming $\operatorname{Tian}^{1,2^{*}}$ (D) and Bing-Nan Jiang ${ }^{2}$
}

\author{
"Correspondence: \\ tianming1963@126.com \\ ${ }^{1}$ Tianjin Key Lab for Advanced \\ Signal Processing, Civil Aviation \\ University of China, Tianjin, China \\ ${ }^{2}$ College of Science, Civil Aviation \\ University of China, Tianjin, China
}

\begin{abstract}
For a variational inequality problem, the inertial projection and contraction method have been studied. It has a weak convergence result. In this paper, we propose a strong convergence iterative method for finding a solution of a variational inequality problem with a monotone mapping by projection and contraction method and inertial hybrid algorithm. Our result can be used to solve other related problems in Hilbert spaces.

MSC: 58E35; 47H09; 65J15

Keywords: Variational inequality problem; Inertial projection and contraction method; Strong convergence; Monotone mapping; Inertial hybrid algorithm; Hilbert spaces
\end{abstract}

\section{Introduction}

The variational inequality (VI) problem plays an important role in nonlinear analysis and optimization. It is a generalization of the nonlinear complementarity problem. Recently, it has had considerable applications in many fields. The VI problem was introduced by Fichera [1, 2] for solving Signorini problem. Later, it was studied by Stampacchia [3] for solving mechanic problems.

Let $H$ be a real Hilbert space with the inner product $\langle\cdot, \cdot\rangle$ and the norm $\|\cdot\|$. Let $C$ be a nonempty closed convex subset of $H$. The variational inequality problem is to find a point $x^{*} \in C$ such that

$$
\left\langle F x^{*}, x-x^{*}\right\rangle \geq 0, \quad \forall x \in C,
$$

where $F$ is a mapping of $H$ into $H$. The solution set of VI (1.1) is denoted by $\operatorname{VI}(C, F)$.

Using properties of the metric projection, we can easily see that $x^{*} \in V I(C, F)$ if and only if

$$
x^{*}=P_{C}(I-\lambda F) x^{*} .
$$

Many scholars are devoted to the research of variational inequality problems. Some authors have proposed several iterative methods for solving VI (1.1). A simple iterative

(c) The Author(s) 2020. This article is licensed under a Creative Commons Attribution 4.0 International License, which permits use, sharing, adaptation, distribution and reproduction in any medium or format, as long as you give appropriate credit to the original author(s) and the source, provide a link to the Creative Commons licence, and indicate if changes were made. The images or other third party material in this article are included in the article's Creative Commons licence, unless indicated otherwise in a credit line to the material. If material is not included in the article's Creative Commons licence and your intended use is not permitted by statutory regulation or exceeds the permitted use, you will need to obtain permission directly from the copyright holder. To view a copy of this licence, visit http://creativecommons.org/licenses/by/4.0/. 
method [4] is

$$
x_{n+1}=P_{C}(I-\lambda F) x_{n},
$$

or more generally,

$$
x_{n+1}=P_{C}\left(I-\lambda_{n} F\right) x_{n} .
$$

The convergence of (1.2) and (1.3) depends on the properties of $F$. If $F$ is strongly monotone and Lipschitz continuous, (1.2) and (1.3) have strong convergence results under certain conditions of parameters. If $F$ is inverse strongly monotone, (1.2) and (1.3) have weak convergence results under some suitable conditions.

In 1976, Korpelevich [5] proposed the following so-called extragradient method for solving VI (1.1) when $F$ is monotone and Lipschitz continuous in the finite-dimensional Euclidean space $\mathbb{R}^{n}$ :

$$
\left\{\begin{array}{l}
x_{1}=x \in C \quad \text { is chosen arbitrarily, } \\
y_{n}=P_{C}\left(x_{n}-\lambda F x_{n}\right) \\
x_{n+1}=P_{C}\left(x_{n}-\lambda F y_{n}\right)
\end{array}\right.
$$

for each $n \in \mathbb{N}$. Under some suitable conditions, the sequences $\left\{x_{n}\right\}$ and $\left\{y_{n}\right\}$ converge to the same point $z \in V I(C, F)$. The recent variants of Korpelevich's method can be found in [6].

In 1997, He [7] proposed another method to solve VI with monotone mappings. His method is called projection and contraction method:

$$
\left\{\begin{array}{l}
x_{1}=x \in C \quad \text { is chosen arbitrarily, } \\
y_{n}=P_{C}\left(x_{n}-\lambda F x_{n}\right) \\
d\left(x_{n}, y_{n}\right)=\left(x_{n}-y_{n}\right)-\lambda\left(F x_{n}-F y_{n}\right) \\
x_{n+1}=x_{n}-\gamma \beta_{n} d\left(x_{n}, y_{n}\right)
\end{array}\right.
$$

for each $n \in \mathbb{N}$, where $\gamma \in(0,2)$,

$$
\beta_{n}= \begin{cases}\frac{\varphi\left(x_{n}, y_{n}\right)}{\left\|d\left(x_{n}, y_{n}\right)\right\|}, & \text { if } d\left(x_{n}, y_{n}\right) \neq 0, \\ 0, & \text { if } d\left(x_{n}, y_{n}\right)=0\end{cases}
$$

and

$$
\varphi\left(x_{n}, y_{n}\right)=\left\langle x_{n}-y_{n}, d\left(x_{n}, y_{n}\right)\right\rangle
$$

This method has a convergence result under certain conditions. 
In 2017, Dong et al. [8] proposed the following so-called inertial projection and contraction method:

$$
\left\{\begin{array}{l}
x_{0}, x_{1} \in H \quad \text { are chosen arbitrarily, } \\
w_{n}=x_{n}+\alpha_{n}\left(x_{n}-x_{n-1}\right), \\
y_{n}=P_{C}\left(w_{n}-\lambda F w_{n}\right), \\
d\left(w_{n}, y_{n}\right)=\left(w_{n}-y_{n}\right)-\lambda\left(F w_{n}-F y_{n}\right), \\
x_{n+1}=w_{n}-\gamma \beta_{n} d\left(x_{n}, y_{n}\right),
\end{array}\right.
$$

for each $n \in \mathbb{N}$, where $\gamma \in(0,2)$,

$$
\beta_{n}= \begin{cases}\frac{\varphi\left(w_{n}, y_{n}\right)}{\left\|d\left(w_{n}, y_{n}\right)\right\|}, & \text { if } d\left(w_{n}, y_{n}\right) \neq 0, \\ 0, & \text { if } d\left(w_{n}, y_{n}\right)=0,\end{cases}
$$

and

$$
\varphi\left(w_{n}, y_{n}\right)=\left\langle w_{n}-y_{n}, d\left(w_{n}, y_{n}\right)\right\rangle
$$

They proved that the sequence $\left\{x_{n}\right\}$ generated by (1.6) converges weakly to a point in $V I(C, F)$ under certain conditions.

Sometimes, a weak convergence result is not very good. We want to get a strong convergence result. Very recently, Dong et al. [9] used hybrid method to modify an inertial forward-backward algorithm for solving zero point problems in Hilbert spaces:

$$
\left\{\begin{aligned}
x_{0}, x_{1} \in H \quad \text { are chosen arbitrarily, } & \\
y_{n}= & x_{n}+\alpha_{n}\left(x_{n}-x_{n-1}\right), \\
z_{n}= & \left(I+r_{n} B\right)^{-1}\left(y_{n}-r_{n} A y_{n}\right), \\
C_{n}= & \left\{u \in H:\left\|z_{n}-u\right\|^{2} \leq\left\|x_{n}-u\right\|^{2}-2 \alpha_{n}\left\langle x_{n}-u, x_{n-1}-x_{n}\right\rangle\right. \\
& \left.\quad+\alpha_{n}^{2}\left\|x_{n-1}-x_{n}\right\|^{2}\right\}, \\
Q_{n}= & \left\{u \in H:\left\langle u-x_{n}, x_{0}-x_{n}\right\rangle \leq 0\right\}, \\
x_{n+1}= & P_{C_{n} \cap Q_{n}} x_{0} .
\end{aligned}\right.
$$

They proved that $\left\{x_{n}\right\}$ converges strongly to $P_{\left.(A+B)^{-1}(0)\right)_{0}}$ under some suitable conditions.

Based on the work above, we propose an inertial hybrid method for finding a solution of a variational inequality problem with a monotone mapping. As applications, we use algorithm we proposed to solve other related problems in Hilbert spaces.

\section{Preliminaries}

In this section, we introduce some mathematical symbols, definitions, and lemmas which can be used in the proofs of our main results.

Throughout this paper, let $\mathbb{N}$ and $\mathbb{R}$ be the sets of positive integers and real numbers, respectively. Let $H$ be a real Hilbert space with the inner product $\langle\cdot, \cdot\rangle$ and norm $\|\cdot\|$. Let $\left\{x_{n}\right\}$ be a sequence in $H$, we write " $x_{n} \rightarrow x$ " to indicate that the sequence $\left\{x_{n}\right\}$ converges weakly to $x$ and " $x_{n} \rightarrow x$ " to indicate that the sequence $\left\{x_{n}\right\}$ converges strongly to $x$. $z$ is 
called a weak cluster point of $\left\{x_{n}\right\}$ if there exists a subsequence $\left\{x_{n_{i}}\right\}$ of $\left\{x_{n}\right\}$ converging weakly to $z$. We write $\omega_{w}\left(x_{n}\right)$ to indicate the set of all weak cluster points of $\left\{x_{n}\right\}$. A fixed point of a mapping $T: H \rightarrow H$ is a point $x \in H$ such that $T x=x$, and we denote the set of all fixed points of mapping $T$ by $F i x(T)$.

We introduce definitions of some operators we will use in the following sections.

Definition 2.1 ([10-12]) Let $T: H \rightarrow H$ be the nonlinear operators.

(i) $T$ is nonexpansive if

$$
\|T x-T y\| \leq\|x-y\|, \quad \forall x, y \in H .
$$

(ii) $T$ is firmly nonexpansive if

$$
\langle T x-T y, x-y\rangle \geq\|T x-T y\|^{2}, \quad \forall x, y \in H .
$$

We can easily show that a firmly nonexpansive mapping is always nonexpansive by using the Cauchy-Schwarz inequality.

(iii) $T$ is $\alpha$-averaged, with $0<\alpha<1$, if

$$
T=(1-\alpha) I+\alpha S
$$

where $S: H \rightarrow H$ is nonexpansive. The term "averaged mapping" was introduced in the early paper by Baillon, Bruck, and Reich [13]. It is obvious that Fix $(S)=F i x(T)$. We can easily show that a firmly nonexpansive mapping is $\frac{1}{2}$-averaged.

(iv) $T$ is $L$-Lipschitz continuous, with $L \geq 0$, if

$$
\|T x-T y\| \leq L\|x-y\|, \quad \forall x, y \in H .
$$

We call $T$ a contractive mapping when $0 \leq L<1$.

Definition 2.2 ([10,11]) Let $F: H \rightarrow H$ be a nonlinear mapping.

(i) $F$ is monotone if

$$
\langle F x-F y, x-y\rangle \geq 0, \quad \forall x, y \in H .
$$

(ii) $F$ is $\eta$-strongly monotone, with $\eta>0$, if

$$
\langle F x-F y, x-y\rangle \geq \eta\|x-y\|^{2}, \quad \forall x, y \in H .
$$

(iii) $F$ is $v$-inverse strongly monotone $(v$-ism), with $v>0$, if

$$
\langle F x-F y, x-y\rangle \geq v\|F x-F y\|^{2}, \quad \forall x, y \in H .
$$

We can easily show that a $v$-ism mapping is $\frac{1}{v}$-Lipschitz continuous by using the Cauchy-Schwarz inequality.

We introduce some definitions and propositions about projections. 
Proposition 2.3 ([4]) Let $C$ be a nonempty closed convex subset of $H$. Then, for each $x \in H$, there exists a unique point $z \in C$ such that

$$
\|x-z\| \leq\|x-y\|, \quad \forall y \in C .
$$

Definition 2.4 ([4]) Let $C$ be a nonempty closed convex subset of $H$. Define

$$
P_{C} x=\arg \min _{y \in C}\|y-x\|, \quad \forall x \in H .
$$

$P_{C}$ is called the metric projection on $C$. We can show that $P_{C}$ is firmly nonexpansive.

Lemma 2.5 ([14, 15]) Let $C$ be a nonempty closed convex subset of a real Hilbert space $H$. Given $x \in H$ and $z \in C$. Then $z=P_{C} x$ if and only if there holds the inequality

$$
\langle x-z, z-y\rangle \geq 0, \quad \forall y \in C .
$$

Lemma 2.6 ([14-16]) Let $C$ be a nonempty closed convex subset of a real Hilbert space $H$. Given $x \in H$ and $z \in C$. Then $z=P_{C} x$ if and only if there holds the inequality

$$
\|x-y\|^{2} \geq\|x-z\|^{2}+\|y-z\|^{2}, \quad \forall y \in C .
$$

More properties of metric projections can be found in [12].

Next, we introduce some definitions and propositions about set-valued mappings.

Definition 2.7 ([17]) Let $H$ be a real Hilbert space. Let $A$ be a set-valued mapping of $H$ into $2^{H}$. We denote the effective domain of $A$ by $D(A), D(A)$ is defined by

$$
D(A)=\{x \in H: A x \neq \emptyset\} .
$$

The graph of $A$ is defined by

$$
G(A)=\{(x, u) \in H \times H: u \in A x\} .
$$

A set-valued mapping $A$ is called monotone if

$$
\langle x-y, u-v\rangle \geq 0, \quad \forall(x, u),(y, v) \in G(A) .
$$

A monotone mapping $A$ is called maximal if its graph is not properly contained in the graph of any other monotone mappings on $D(A)$.

In fact, we cannot use the definition of the maximal monotone mapping conveniently, a property of the maximal monotone mapping is usually used: A monotone mapping $B$ is maximal if and only if for $(x, u) \in H \times H,\langle x-y, u-v\rangle \geq 0$ for each $(y, v) \in G(A)$ implies $(x, u) \in G(A)$. This property is just a reformulation of the definition of maximal monotone mappings. 
Definition $2.8([17,18])$ Let $A: H \rightarrow 2^{H}$ be a mapping and $r>0$. The resolvent of $A$ is

$$
J_{r}^{A}:=(I+r A)^{-1} .
$$

Lemma 2.9 $([17,18])$ Let $A: H \rightarrow 2^{H}$ be a maximal monotone mapping and $r>0$. Then $J_{r}^{A}: H \rightarrow D(A)$ is firmly nonexpansive.

In particular, let $C$ be a nonempty closed convex subset of a real Hilbert space $H$, recall the normal cone [19] to $C$ at $x \in C$ :

$$
N_{C} x=\{z \in H:\langle z, y-x\rangle \leq 0, \forall y \in C\} .
$$

We can easily show that $N_{C}$ is a maximal monotone mapping and its resolvent is $P_{C}$. So we can consider the resolvent of a maximal monotone mapping as a generalization of metric projection operator.

Lemma 2.10 ([19]) Let $C$ be a nonempty closed convex subset of a real Hilbert space $H$. Let $F$ be a monotone and Lipschitz continuous mapping of $C$ into H. Define

$$
T v= \begin{cases}F v+N_{C} v, & \forall v \in C, \\ \emptyset, & \forall v \notin C .\end{cases}
$$

Then $T$ is maximal monotone and $0 \in T v$ if and only if $v \in V I(C, F)$.

\section{Main result}

In this section, we propose a strong convergence algorithm for finding a solution of a variational inequality problem. The algorithm we propose is based on the work in Sect. 1 .

Let $H$ be a real Hilbert space. Let $C$ be a nonempty closed convex subset of $H$. Let $F$ be a mapping of $H$ into $H$.

Algorithm 1 Choose $x_{0}, x_{1} \in H$ arbitrarily. Calculate the $(n+1)$ th iterate $x_{n+1}$ via the formula

$$
\left\{\begin{aligned}
w_{n}= & x_{n}+\alpha_{n}\left(x_{n}-x_{n-1}\right), \\
y_{n}= & P_{C}\left(w_{n}-\lambda_{n} F w_{n}\right), \\
d\left(w_{n}, y_{n}\right)=\left(w_{n}-y_{n}\right)-\lambda_{n}\left(F w_{n}-F y_{n}\right), & z_{n}=w_{n}-\gamma \beta_{n} d\left(w_{n}, y_{n}\right), \\
C_{n}= & \left\{u \in H:\left\|z_{n}-u\right\|^{2} \leq\left\|x_{n}-u\right\|^{2}-2 \alpha_{n}\left\langle x_{n}-u, x_{n-1}-x_{n}\right\rangle\right. \\
& \left.+\alpha_{n}^{2}\left\|x_{n-1}-x_{n}\right\|^{2}\right\}, \\
Q_{n}= & \left\{u \in H:\left\langle u-x_{n}, x_{1}-x_{n}\right\rangle \leq 0\right\}, \\
x_{n+1}= & P_{C_{n} \cap Q_{n} x_{1},}
\end{aligned}\right.
$$

for each $n \geq 1$, where $\gamma \in(0,2), \lambda_{n}>0$, and

$$
\beta_{n}= \begin{cases}\frac{\varphi\left(w_{n}, y_{n}\right)}{\left\|d\left(w_{n}, y_{n}\right)\right\|}, & \text { if } d\left(w_{n}, y_{n}\right) \neq 0, \\ 0, & \text { if } d\left(w_{n}, y_{n}\right)=0,\end{cases}
$$


where

$$
\varphi\left(w_{n}, y_{n}\right)=\left\langle w_{n}-y_{n}, d\left(w_{n}, y_{n}\right)\right\rangle
$$

If $y_{n}=w_{n}$ or $d\left(w_{n}, y_{n}\right)=0$, then calculate $x_{n+1}$ and the iterative process stops; otherwise, we set $n:=n+1$ and go on to (3.1) to calculate the next iterate $x_{n+2}$.

Theorem 3.1 Let $C$ be a nonempty closed convex subset of a real Hilbert space H. Let $F: H \rightarrow H$ be a monotone and L-Lipschitz continuous mapping with $L>0$. Assume that $V I(C, F) \neq \emptyset$ and $0<a \leq \lambda_{n} \leq b<\frac{1}{L}$. Let $\left\{x_{n}\right\}$ be a sequence generated by Algorithm 1 . If $y_{n}=w_{n}$ or $d\left(w_{n}, y_{n}\right)=0$, then $x_{n+1} \in V I(C, F)$.

Proof From the expression of $d\left(w_{n}, y_{n}\right)$ and the condition imposed on $F$, we have

$$
\begin{aligned}
& \left\|d\left(w_{n}, y_{n}\right)\right\| \\
& \quad=\left\|\left(w_{n}-y_{n}\right)-\lambda_{n}\left(F w_{n}-F y_{n}\right)\right\| \\
& \geq\left\|w_{n}-y_{n}\right\|-\lambda_{n}\left\|F w_{n}-F y_{n}\right\| \\
& \geq\left\|w_{n}-y_{n}\right\|-\lambda_{n} L\left\|w_{n}-y_{n}\right\| \\
& \geq(1-b L)\left\|w_{n}-y_{n}\right\| .
\end{aligned}
$$

On the other hand,

$$
\begin{aligned}
& \left\|d\left(w_{n}, y_{n}\right)\right\| \\
& \quad=\left\|\left(w_{n}-y_{n}\right)-\lambda_{n}\left(F w_{n}-F y_{n}\right)\right\| \\
& \leq\left\|w_{n}-y_{n}\right\|+\lambda_{n}\left\|F w_{n}-F y_{n}\right\| \\
& \leq\left\|w_{n}-y_{n}\right\|+\lambda_{n} L\left\|w_{n}-y_{n}\right\| \\
& \leq(1+b L)\left\|w_{n}-y_{n}\right\| .
\end{aligned}
$$

So we have

$$
(1-b L)\left\|w_{n}-y_{n}\right\| \leq\left\|d\left(w_{n}, y_{n}\right)\right\| \leq(1+b L)\left\|w_{n}-y_{n}\right\| .
$$

Hence $y_{n}=w_{n}$ and $d\left(w_{n}, y_{n}\right)=0$ are equivalent. Using Lemma 2.5, we can get the desired result.

Theorem 3.2 Let $C$ be a nonempty closed convex subset of a real Hilbert space H. Let $F: H \rightarrow H$ be a monotone and L-Lipschitz continuous mapping with $L>0$. Assume that $V I(C, F) \neq \emptyset$ and $0<a \leq \lambda_{n} \leq b<\frac{1}{L}$. Let $\left\{x_{n}\right\}$ be a sequence generated by Algorithm 1 . If $y_{n} \neq w_{n}$ for each $n \in N$, then $\left\{x_{n}\right\}$ converges strongly to $x^{*}=P_{V I(C, F)} x_{1}$.

Proof We divide the proof into four steps.

Step 1. We show that $V I(C, F) \subset C_{n} \cap Q_{n}$ for each $n \in \mathbb{N}$. 
It is obvious that $C_{n}$ and $Q_{n}$ are half-spaces for each $n \in \mathbb{N}$.

$$
\begin{aligned}
\varphi & \left(w_{n}, y_{n}\right) \\
& =\left\langle w_{n}-y_{n}, d\left(w_{n}, y_{n}\right)\right\rangle \\
& =\left\langle w_{n}-y_{n},\left(w_{n}-y_{n}\right)-\lambda_{n}\left(F w_{n}-F y_{n}\right)\right\rangle \\
& =\left\|w_{n}-y_{n}\right\|^{2}-\lambda_{n}\left\langle w_{n}-y_{n}, F w_{n}-F y_{n}\right\rangle \\
& \geq\left\|w_{n}-y_{n}\right\|^{2}-\lambda_{n}\left\|w_{n}-y_{n}\right\|\left\|F w_{n}-F y_{n}\right\| \\
& \geq\left\|w_{n}-y_{n}\right\|^{2}-b L\left\|w_{n}-y_{n}\right\|^{2} \\
& =(1-b L)\left\|w_{n}-y_{n}\right\|^{2} .
\end{aligned}
$$

On the other hand,

$$
\begin{aligned}
\| & d\left(w_{n}, y_{n}\right) \|^{2} \\
& =\left\|\left(w_{n}-y_{n}\right)-\lambda_{n}\left(F w_{n}-F y_{n}\right)\right\|^{2} \\
& =\left\|w_{n}-y_{n}\right\|^{2}+\lambda_{n}^{2}\left\|F w_{n}-F y_{n}\right\|^{2}-2 \lambda_{n}\left\langle w_{n}-y_{n}, F w_{n}-F y_{n}\right\rangle \\
& \leq\left\|w_{n}-y_{n}\right\|^{2}+\lambda_{n}^{2}\left\|F w_{n}-F y_{n}\right\|^{2} \\
& \leq\left\|w_{n}-y_{n}\right\|^{2}+b^{2} L^{2}\left\|w_{n}-y_{n}\right\|^{2} \\
& =\left(1+b^{2} L^{2}\right)\left\|w_{n}-y_{n}\right\|^{2} .
\end{aligned}
$$

Combining (3.3) and (3.4), we have

$$
\beta_{n}=\frac{\varphi\left(w_{n}, y_{n}\right)}{\left\|d\left(w_{n}, y_{n}\right)\right\|^{2}} \geq \frac{1-b L}{1+b^{2} L^{2}}
$$

Let $u \in V I(C, F)$, we have

$$
\begin{aligned}
\left\|z_{n}-u\right\|^{2} \\
=\left\|w_{n}-\gamma \beta_{n} d\left(w_{n}, y_{n}\right)-u\right\|^{2} \\
=\left\|w_{n}-u\right\|^{2}-2 \gamma \beta_{n}\left\langle w_{n}-u, d\left(w_{n}, y_{n}\right)\right\rangle+\gamma^{2} \beta_{n}^{2}\left\|d\left(w_{n}, y_{n}\right)\right\|^{2} \\
=\left\|w_{n}-u\right\|^{2}-2 \gamma \beta_{n}\left\langle w_{n}-y_{n}, d\left(w_{n}, y_{n}\right)\right\rangle-2 \gamma \beta_{n}\left\langle y_{n}-u, d\left(w_{n}, y_{n}\right)\right\rangle \\
\quad+\gamma^{2} \beta_{n}^{2}\left\|d\left(w_{n}, y_{n}\right)\right\|^{2} .
\end{aligned}
$$

By the definition of $y_{n}$ and Lemma 2.5,

$$
\left\langle y_{n}-u, w_{n}-y_{n}-\lambda_{n} F w_{n}\right\rangle \geq 0 \text {. }
$$

So we have

$$
\begin{aligned}
& \left\langle y_{n}-u, d\left(w_{n}, y_{n}\right)\right\rangle \\
& \quad=\left\langle y_{n}-u, w_{n}-y_{n}-\lambda_{n}\left(F w_{n}-F y_{n}\right)\right\rangle
\end{aligned}
$$




$$
\begin{aligned}
& =\left\langle y_{n}-u, w_{n}-y_{n}-\lambda_{n} F w_{n}\right\rangle+\lambda_{n}\left\langle y_{n}-u, F y_{n}-F u\right\rangle+\lambda_{n}\left\langle y_{n}-u, F u\right\rangle \\
& \geq 0 .
\end{aligned}
$$

Combining (3.6) and (3.7), we get

$$
\begin{aligned}
\| z_{n} & -u \|^{2} \\
& \leq\left\|w_{n}-u\right\|^{2}-2 \gamma \beta_{n}\left\langle w_{n}-y_{n}, d\left(w_{n}, y_{n}\right)\right\rangle+\gamma^{2} \beta_{n}^{2}\left\|d\left(w_{n}, y_{n}\right)\right\|^{2} \\
& =\left\|w_{n}-u\right\|^{2}-2 \gamma \beta_{n} \varphi\left(w_{n}, y_{n}\right)+\gamma^{2} \beta_{n}^{2}\left\|d\left(w_{n}, y_{n}\right)\right\|^{2} \\
& =\left\|w_{n}-u\right\|^{2}-2 \gamma \beta_{n}^{2}\left\|d\left(w_{n}, y_{n}\right)\right\|^{2}+\gamma^{2} \beta_{n}^{2}\left\|d\left(w_{n}, y_{n}\right)\right\|^{2} \\
& =\left\|w_{n}-u\right\|^{2}-\gamma(2-\gamma) \beta_{n}^{2}\left\|d\left(w_{n}, y_{n}\right)\right\|^{2} \\
& =\left\|w_{n}-u\right\|^{2}-\frac{2-\gamma}{\gamma}\left\|z_{n}-w_{n}\right\|^{2} \\
& \leq\left\|w_{n}-u\right\|^{2} .
\end{aligned}
$$

By the expression of $w_{n}$, we have

$$
\begin{aligned}
& \left\|w_{n}-u\right\|^{2} \\
& \quad=\left\|\left(x_{n}-u\right)-\alpha_{n}\left(x_{n-1}-x_{n}\right)\right\|^{2} \\
& \quad=\left\|x_{n}-u\right\|^{2}-2 \alpha_{n}\left\langle x_{n}-u, x_{n-1}-x_{n}\right\rangle+\alpha_{n}^{2}\left\|x_{n-1}-x_{n}\right\|^{2} .
\end{aligned}
$$

It follows from (3.8) and (3.9) that

$$
\begin{aligned}
& \left\|z_{n}-u\right\|^{2} \\
& \quad \leq\left\|w_{n}-u\right\|^{2} \\
& \quad=\left\|x_{n}-u\right\|^{2}-2 \alpha_{n}\left\langle x_{n}-u, x_{n-1}-x_{n}\right\rangle+\alpha_{n}^{2}\left\|x_{n-1}-x_{n}\right\|^{2} .
\end{aligned}
$$

Therefore, $u \in C_{n}$ for each $n \in \mathbb{N}$. Hence, $V I(C, F) \subset C_{n}$ for each $n \in \mathbb{N}$.

For $n=1$, we have $Q_{1}=H$ and hence $V I(C, F) \subset C_{1} \cap Q_{1}$.

Suppose that $x_{k}$ is given and $V I(C, F) \subset C_{k} \cap Q_{k}$ for some $k \in \mathbb{N}$. It follows from $x_{k+1}$ and Lemma 2.5 that

$$
\left\langle y-x_{k+1}, x_{1}-x_{k+1}\right\rangle \leq 0, \quad \forall y \in V I(C, F) .
$$

It means that $V I(C, F) \subset Q_{k+1}$. Hence, $V I(C, F) \subset C_{k+1} \cap Q_{k+1}$.

By induction, we obtain $V I(C, F) \subset C_{n} \cap Q_{n}$ for each $n \in \mathbb{N}$.

Step 2. We show that $\left\{x_{n}\right\}$ is bounded.

From

$$
\left\langle y-x_{n}, x_{1}-x_{n}\right\rangle \leq 0, \quad \forall y \in Q_{n}
$$

and Lemma 2.5, we have

$$
x_{n}=P_{Q_{n}} x_{1}
$$


and hence

$$
\left\|x_{n}-x_{1}\right\| \leq\left\|x_{1}-y\right\|, \quad \forall y \in Q_{n} .
$$

Since $V I(C, F) \subset Q_{n}$, we have

$$
\left\|x_{n}-x_{1}\right\| \leq\left\|x_{1}-y\right\|, \quad \forall y \in V I(C, F) .
$$

In particular, since $x_{n+1} \in Q_{n}$, we obtain

$$
\left\|x_{n}-x_{1}\right\| \leq\left\|x_{n+1}-x_{1}\right\| .
$$

Therefore, there exists

$$
c=\lim _{n \rightarrow \infty}\left\|x_{n}-x_{1}\right\| .
$$

It means that $\left\{x_{n}\right\}$ is bounded.

Step 3. We show that $\omega_{w}\left(x_{n}\right) \subset V I(C, F)$.

Since $x_{n}=P_{Q_{n}} x_{1}, x_{n+1} \in Q_{n}$ and Lemma 2.6, we obtain

$$
\left\|x_{n+1}-x_{n}\right\|^{2} \leq\left\|x_{n+1}-x_{1}\right\|^{2}-\left\|x_{n}-x_{1}\right\|^{2},
$$

and hence

$$
x_{n+1}-x_{n} \rightarrow 0, \quad n \rightarrow \infty .
$$

From

$$
\begin{aligned}
\left\|w_{n}-x_{n}\right\| & =\left\|x_{n}-\alpha_{n}\left(x_{n}-x_{n-1}\right)-x_{n}\right\| \\
& =\alpha_{n}\left\|x_{n}-x_{n-1}\right\|
\end{aligned}
$$

and that $\left\{x_{n}\right\}$ is bounded, we have

$$
w_{n}-x_{n} \rightarrow 0, \quad n \rightarrow \infty
$$

Since $x_{n+1} \in C_{n}$, we have

$$
\begin{aligned}
\left\|z_{n}-x_{n+1}\right\|^{2} & \leq\left\|x_{n}-x_{n+1}\right\|^{2}-2 \alpha_{n}\left\langle x_{n}-x_{n+1}, x_{n-1}-x_{n}\right\rangle+\alpha_{n}^{2}\left\|x_{n-1}-x_{n}\right\|^{2} \\
& \leq\left\|x_{n}-x_{n+1}\right\|^{2}+2 \alpha_{n}\left\|x_{n}-x_{n+1}\right\|\left\|x_{n-1}-x_{n}\right\|+\alpha_{n}^{2}\left\|x_{n-1}-x_{n}\right\|^{2}
\end{aligned}
$$

and hence

$$
z_{n}-x_{n+1} \rightarrow 0, \quad n \rightarrow \infty .
$$

Combining (3.14), (3.15), and (3.16), we obtain

$$
z_{n}-w_{n} \rightarrow 0, \quad n \rightarrow \infty .
$$


From (3.1), (3.2), (3.5), and (3.17), we have

$$
w_{n}-y_{n} \rightarrow 0, \quad n \rightarrow \infty
$$

Since $\left\{x_{n}\right\}$ is bounded, we can take a suitable subsequence $\left\{x_{n_{i}}\right\}$ such that $x_{n_{i}} \rightarrow z$. So we have $w_{n_{i}} \rightarrow z$ and $y_{n_{i}} \rightarrow z$. Let

$$
T v= \begin{cases}F v+N_{C} v, & v \in C, \\ \emptyset, & v \notin C .\end{cases}
$$

Then from Lemma 2.10, we know that $T$ is maximal monotone and $0 \in T v$ if and only if $v \in V I(C, F)$. For each $(v, w) \in G(T)$, we have

$$
w \in T v=F v+N_{C} v
$$

and hence

$$
w-F v \in N_{C} v
$$

By the definition of $N_{C}$, we obtain

$$
\langle v-p, w-F v\rangle \geq 0, \quad \forall p \in C .
$$

On the other hand, from $v \in C$ and the expression of $y_{n}$, we have

$$
\left\langle w_{n}-\lambda_{n} F w_{n}-y_{n}, y_{n}-v\right\rangle \geq 0
$$

and hence

$$
\left\langle v-y_{n}, \frac{y_{n}-w_{n}}{\lambda_{n}}+F w_{n}\right\rangle \geq 0 .
$$

Therefore, from (3.19) and (3.20), we obtain

$$
\begin{aligned}
& \left\langle v-y_{n_{i}}, w\right\rangle \\
& \quad \geq\left\langle v-y_{n_{i}}, F v\right\rangle \\
& \geq\left\langle v-y_{n_{i}}, F v\right\rangle-\left\langle v-y_{n_{i}}, \frac{y_{n_{i}}-w_{n_{i}}}{\lambda_{n_{i}}}+F w_{n_{i}}\right\rangle \\
& =\left\langle v-y_{n_{i}}, F v-F w_{n_{i}}\right\rangle-\left\langle v-y_{n_{i}}, \frac{y_{n_{i}}-w_{n_{i}}}{\lambda_{n_{i}}}\right\rangle \\
& =\left\langle v-y_{n_{i}}, F v-F y_{n_{i}}\right\rangle+\left\langle v-y_{n_{i}}, F y_{n_{i}}-F w_{n_{i}}\right\rangle-\left\langle v-y_{n_{i}}, \frac{y_{n_{i}}-w_{n_{i}}}{\lambda_{n_{i}}}\right\rangle \\
& \geq+\left\langle v-y_{n_{i}}, F y_{n_{i}}-F w_{n_{i}}\right\rangle-\left\langle v-y_{n_{i}}, \frac{y_{n_{i}}-w_{n_{i}}}{\lambda_{n_{i}}}\right\rangle .
\end{aligned}
$$


As $i \rightarrow \infty$, we have

$$
\langle v-z, w\rangle \geq 0
$$

Since $T$ is maximal monotone, we have $0 \in T z$ and hence $z \in V I(C, F)$. So we obtain $\omega_{w}\left(x_{n}\right) \subset V I(C, F)$.

Step 4. We show that $x_{n} \rightarrow x^{*}$ as $n \rightarrow \infty$.

Since the norm is convex and lower continuous and $z \in V I(C, F)$, it follows from (3.11) that

$$
\left\|x_{1}-x^{*}\right\| \leq\left\|x_{1}-z\right\| \leq \liminf _{i \rightarrow \infty}\left\|x_{n_{i}}-x_{1}\right\| \leq \limsup _{i \rightarrow \infty}\left\|x_{n_{i}}-x_{1}\right\| \leq\left\|x_{1}-x^{*}\right\| .
$$

So we have

$$
\lim _{i \rightarrow \infty}\left\|x_{n_{i}}-x_{1}\right\|=\left\|x_{1}-z\right\|=\left\|x_{1}-x^{*}\right\| .
$$

From $x^{*}=P_{V I(C, F)} x_{1}$, we obtain $z=x^{*}$, i.e., $\omega_{w}\left(x_{n}\right)=\left\{x^{*}\right\}$. So we have

$$
\lim _{n \rightarrow \infty}\left\|x_{n}-x_{1}\right\|=\left\|x_{1}-x^{*}\right\|
$$

and

$$
x_{n} \rightarrow x^{*}, \quad n \rightarrow \infty .
$$

Hence $x_{n}-x_{1} \rightarrow x^{*}-x_{1}$. Since $H$ satisfies the K-K property, we can obtain $x_{n}-x_{1} \rightarrow x^{*}-x_{1}$, i.e., $x_{n} \rightarrow x^{*}$.

Remark 3.3 If we set $\alpha_{n}=0$ for each $n \in \mathbb{N}$, we can get the following algorithm:

$$
\left\{\begin{array}{l}
y_{n}=P_{C}\left(x_{n}-\lambda_{n} F x_{n}\right), \\
d\left(x_{n}, y_{n}\right)=\left(x_{n}-y_{n}\right)-\lambda_{n}\left(F x_{n}-F y_{n}\right), \\
z_{n}=x_{n}-\gamma \beta_{n} d\left(x_{n}, y_{n}\right), \\
C_{n}=\left\{u \in H:\left\|z_{n}-u\right\|^{2} \leq\left\|x_{n}-u\right\|^{2}\right\}, \\
Q_{n}=\left\{u \in H:\left\langle u-x_{n}, x_{1}-x_{n}\right\rangle \leq 0\right\}, \\
x_{n+1}=P_{C_{n} \cap Q_{n}} x_{1} .
\end{array}\right.
$$

\section{Applications}

In this section, we introduce some applications which are useful in nonlinear analysis and optimization problems in Hilbert spaces.

\subsection{Constrained convex minimization problem}

Let $C$ be a nonempty closed convex subset of a real Hilbert space $H$. The constrained convex minimization problem [14] is to find a point $x^{*} \in C$ such that

$$
f\left(x^{*}\right)=\min _{x \in C} f(x)
$$

where $f$ is a real-valued convex function. We denote the solution set of problem (4.1) by $\Omega$. 
We need the following lemma.

Lemma 4.1 $([11,20])$ Let $H$ be real Hilbert space, and let $C$ be a nonempty closed convex subset of $H$. Let $f$ be a convex function of $H$ into $\mathbb{R}$. If $f$ is differentiable, then $z \in \Omega$ if and only if $z \in V I(C, \nabla f)$.

Let $H$ be a real Hilbert space. Let $C$ be a nonempty closed convex subset of $H$. Let $f$ be a real-valued convex function of $H$. Assume that $f$ is differentiable.

Algorithm 2 Choose $x_{0}, x_{1} \in H$ arbitrarily. Calculate the $(n+1)$ th iterate $x_{n+1}$ via the formula

$$
\left\{\begin{aligned}
w_{n}=x_{n}+\alpha_{n}\left(x_{n}-x_{n-1}\right), \\
y_{n}=P_{C}\left(w_{n}-\lambda_{n} \nabla f\left(w_{n}\right)\right), \\
d\left(w_{n}, y_{n}\right)=\left(w_{n}-y_{n}\right)-\lambda_{n}\left(\nabla f\left(w_{n}\right)-\nabla f\left(y_{n}\right)\right), \\
z_{n}=w_{n}-\gamma \beta_{n} d\left(w_{n}, y_{n}\right), \\
C_{n}=\left\{u \in H:\left\|z_{n}-u\right\|^{2} \leq\left\|x_{n}-u\right\|^{2}-2 \alpha_{n}\left\langle x_{n}-u, x_{n-1}-x_{n}\right\rangle\right. \\
\left.\quad+\alpha_{n}^{2}\left\|x_{n-1}-x_{n}\right\|^{2}\right\}, \\
Q_{n}=\left\{u \in H:\left\langle u-x_{n}, x_{1}-x_{n}\right\rangle \leq 0\right\}, \\
x_{n+1}=P_{C_{n} \cap Q_{n}} x_{1},
\end{aligned}\right.
$$

for each $n \geq 1$, where $\gamma \in(0,2), \lambda_{n}>0$ and

$$
\beta_{n}= \begin{cases}\frac{\varphi\left(w_{n}, y_{n}\right)}{\left\|d\left(w_{n}, y_{n}\right)\right\|}, & \text { if } d\left(w_{n}, y_{n}\right) \neq 0, \\ 0, & \text { if } d\left(w_{n}, y_{n}\right)=0,\end{cases}
$$

where

$$
\varphi\left(w_{n}, y_{n}\right)=\left\langle w_{n}-y_{n}, d\left(w_{n}, y_{n}\right)\right\rangle
$$

If $y_{n}=w_{n}$ or $d\left(w_{n}, y_{n}\right)=0$, then calculate $x_{n+1}$ and the iterative process stops; otherwise, we set $n:=n+1$ and go on to (4.2) to calculate the next iterate $x_{n+2}$.

Theorem 4.2 Let $C$ be a nonempty closed convex subset of a real Hilbert space H. Let $f$ be real-valued convex function of $H$. Assume that $f$ is differentiable and $\nabla f$ is L-Lipschitz continuous with $L>0$. Assume that $\Omega \neq \emptyset$ and $0<a \leq \lambda_{n} \leq b<\frac{1}{L}$. Let $\left\{x_{n}\right\}$ be a sequence generated by Algorithm 2. If $y_{n}=w_{n}$ or $d\left(w_{n}, y_{n}\right)=0$, then $x_{n+1} \in \Omega$.

Proof Since $f$ is convex, we conclude that $\nabla f$ is monotone. Putting $F=\nabla f$ in Theorem 3.1, we get the desired result by Lemma 4.1.

Theorem 4.3 Let $C$ be a nonempty closed convex subset of a real Hilbert space $H$. Let $F: H \rightarrow H$ be a monotone and L-Lipschitz continuous mapping with $L>0$. Assume that $V I(C, F) \neq \emptyset$ and $0<a \leq \lambda_{n} \leq b<\frac{1}{L}$. Let $\left\{x_{n}\right\}$ be a sequence generated by Algorithm 2. If $y_{n} \neq w_{n}$ for each $n \in N$, then $\left\{x_{n}\right\}$ converges strongly to $x^{*}=P_{\Omega} x_{1}$. 
Proof Since $f$ is convex, we conclude that $\nabla f$ is monotone. Putting $F=\nabla f$ in Theorem 3.2, we get the desired result by Lemma 4.1 .

\subsection{Split feasibility problem}

Next, we consider the split feasibility problem.

The split feasibility problem (SFP) was proposed by Censor and Elfving [21] in 1994. The SFP is to find a point $x^{*}$ such that

$$
x^{*} \in C \text { and } A x^{*} \in Q \text {, }
$$

where $C$ and $Q$ are nonempty closed convex subsets of real Hilbert spaces $H_{1}$ and $H_{2}$, respectively, $A$ is a bounded linear operator of $H_{1}$ and $H_{2}$ with $A \neq 0$.

In 2004, Byrne [22] proposed the following algorithm for solving (4.3):

$$
x_{n+1}=P_{C}\left(x_{n}-\gamma_{n} A^{*}\left(I-P_{Q}\right) A x_{n}\right) .
$$

In this section, we introduce a new algorithm to solve (4.3). We need the following lemmas.

Lemma 4.4 ([20]) Let $H_{1}$ and $H_{2}$ be real Hilbert spaces. Let $C$ and $Q$ be nonempty closed convex subsets of $H_{1}$ and $H_{2}$, respectively. Let $A$ be a bounded linear operator of $H_{1}$ into $H_{2}$ with $A \neq 0$. Assume that $C \cap A^{-1} Q$ is nonempty. Let $\lambda \geq 0$. Then $z \in C \cap A^{-1} Q$ if and only if $z \in V I\left(C, A^{*}\left(I-P_{Q}\right) A\right)$, where $A^{*}$ is the adjoint operator of $A$.

Lemma 4.5 ([20]) Let $H_{1}$ and $H_{2}$ be real Hilbert spaces. Let $A$ be a bounded linear operator of $H_{1}$ into $H_{2}$ such that $A \neq 0$. Let $Q$ be a nonempty closed convex subset of $H_{2}$. Then $A^{*}(I-$ $\left.P_{Q}\right) A$ is monotone and $\|A\|^{2}$-Lipschitz continuous.

We propose the following algorithm for solving SFP (4.3).

Algorithm 3 Choose $x_{0}, x_{1} \in H_{1}$ arbitrarily. Calculate the $(n+1)$ th iterate $x_{n+1}$ via the formula

$$
\left\{\begin{array}{l}
w_{n}=x_{n}+\alpha_{n}\left(x_{n}-x_{n-1}\right), \\
y_{n}=P_{C}\left(w_{n}-\lambda_{n} A^{*}\left(I-P_{Q}\right) A w_{n}\right), \\
d\left(w_{n}, y_{n}\right)=\left(w_{n}-y_{n}\right)-\lambda_{n}\left(A^{*}\left(I-P_{Q}\right) A w_{n}-A^{*}\left(I-P_{Q}\right) A y_{n}\right), \\
z_{n}=w_{n}-\gamma \beta_{n} d\left(w_{n}, y_{n}\right), \\
C_{n}=\left\{u \in H:\left\|z_{n}-u\right\|^{2} \leq\left\|x_{n}-u\right\|^{2}-2 \alpha_{n}\left\langle x_{n}-u, x_{n-1}-x_{n}\right\rangle\right. \\
\left.\quad+\alpha_{n}^{2}\left\|x_{n-1}-x_{n}\right\|^{2}\right\}, \\
Q_{n}=\left\{u \in H:\left\langle u-x_{n}, x_{1}-x_{n}\right\rangle \leq 0\right\}, \\
x_{n+1}=P_{C_{n} \cap Q_{n}} x_{1},
\end{array}\right.
$$

for each $n \geq 1$, where $\gamma \in(0,2), \lambda_{n}>0$, and

$$
\beta_{n}= \begin{cases}\frac{\varphi\left(w_{n}, y_{n}\right)}{\left\|d\left(w_{n}, y_{n}\right)\right\|}, & \text { if } d\left(w_{n}, y_{n}\right) \neq 0 \\ 0, & \text { if } d\left(w_{n}, y_{n}\right)=0\end{cases}
$$


where

$$
\varphi\left(w_{n}, y_{n}\right)=\left\langle w_{n}-y_{n}, d\left(w_{n}, y_{n}\right)\right\rangle
$$

If $y_{n}=w_{n}$ or $d\left(w_{n}, y_{n}\right)=0$, then calculate $x_{n+1}$ and the iterative process stops; otherwise, we set $n:=n+1$ and go on to (4.5) to calculate the next iterate $x_{n+2}$.

Theorem 4.6 Let $C$ and $Q$ be nonempty closed convex subsets of real Hilbert spaces $H_{1}$ and $H_{2}$, respectively. Let $A$ be a bounded linear operator with $A \neq 0$. Set $\Gamma=C \cap A^{-1} Q$. Assume that $\Gamma \neq \emptyset$ and $0<a \leq \lambda_{n} \leq b<\frac{1}{L}$. Let $\left\{x_{n}\right\}$ be a sequence generated by Algorithm 3. If $y_{n}=w_{n}$ or $d\left(w_{n}, y_{n}\right)=0$, then $x_{n+1} \in \Gamma$.

Proof Putting $F=A^{*}\left(I-P_{Q}\right) A$ in Theorem 3.1, we get the desired result by Lemmas 4.4 and 4.5.

Theorem 4.7 Let $C$ and $Q$ be nonempty closed convex subsets of real Hilbert spaces $H_{1}$ and $H_{2}$, respectively. Let $A$ be a bounded linear operator with $A \neq 0$. Set $\Gamma=C \cap A^{-1} Q$. Assume that $\Gamma \neq \emptyset$ and $0<a \leq \lambda_{n} \leq b<\frac{1}{L}$. Let $\left\{x_{n}\right\}$ be a sequence generated by Algorithm 3. If $y_{n} \neq w_{n}$ for each $n \in N$, then $\left\{x_{n}\right\}$ converges strongly to $x^{*}=P_{\Gamma} x_{1}$.

Proof Putting $F=A^{*}\left(I-P_{Q}\right) A$ in Theorem 3.2, we get the desired result by Lemmas 4.4 and 4.5.

\section{Numerical experiments}

In this section, we give some numerical results to illustrate the effectiveness of our iterative scheme in Sect. 3 and compare with extragradient method [5] and iterative scheme (1.2). All the programs are written in Matlab 7.10 and performed on a PC Desktop Intel ${ }^{\circ} \mathrm{Core}^{\text {tm }}$ i5-2450M CPU @ 2.50 GHz 2.50 GHz, RAM 4.00 GB. All the projections over $C$ and $C_{n} \cap Q_{n}$ are computed effectively by the function quadprog in Matlab 7.10 Optimization Toolbox.

Example 1 Let $H=\mathbb{R}$ and $C=[-2,5]$. Let $F$ be a function given by

$$
F x:=x+\sin x
$$

for each $x \in \mathbb{R}$. For all $x, y \in H$, we have

$$
\begin{aligned}
& \|F x-F y\|=\|x+\sin x-y-\sin y\| \leq\|x-y\|+\|\sin x-\sin y\| \leq 2\|x-y\|, \\
& \langle F x-F y, x-y\rangle=(x+\sin x-y-\sin y)(x-y)=(x-y)^{2}+(\sin x-\sin y)(x-y) \geq 0 .
\end{aligned}
$$

Therefore, $F$ is monotone and 2-Lipschitz continuous.

Choose $x_{0}=2, \lambda_{n}=\lambda, \alpha_{n}=2$, and $\gamma=1$ for our iterative scheme (3.1). It is easy to find that $V I(C, F)=\{0\}$. We denote $x^{*}=0$ and use $\left\|x_{n}-x^{*}\right\| \leq 10^{-5}$ for stopping criterion. The numerical results for this example are described in Table 1. 
Table 1 Numerical results as regards Example 1

\begin{tabular}{|c|c|c|c|c|c|c|c|}
\hline \multirow[t]{2}{*}{$x_{1}$} & \multirow[t]{2}{*}{$\lambda$} & \multicolumn{2}{|c|}{ Alg. (3.1) } & \multicolumn{2}{|c|}{ Extragradient method } & \multicolumn{2}{|c|}{ Alg. (1.2) } \\
\hline & & Iter. & Time $[\mathrm{s}]$ & Iter. & Time $[\mathrm{s}]$ & Iter. & Time $[s]$ \\
\hline \multirow[t]{3}{*}{1} & 0.05 & 82 & 4.89 & 124 & 8.52 & 111 & 4.32 \\
\hline & 0.02 & 178 & 9.42 & 297 & 19.45 & 285 & 9.87 \\
\hline & 0.01 & 177 & 8.60 & 585 & 39.08 & 574 & 19.35 \\
\hline \multirow[t]{3}{*}{2} & 0.05 & 97 & 5.53 & 132 & 8.95 & 119 & 4.47 \\
\hline & 0.02 & 81 & 4.81 & 317 & 20.57 & 305 & 12.14 \\
\hline & 0.01 & 138 & 7.11 & 627 & 41.91 & 615 & 20.62 \\
\hline \multirow[t]{3}{*}{3} & 0.05 & 94 & 5.36 & 139 & 9.40 & 126 & 4.64 \\
\hline & 0.02 & 234 & 11.63 & 334 & 21.41 & 321 & 12.92 \\
\hline & 0.01 & 190 & 9.15 & 659 & 42.03 & 647 & 22.89 \\
\hline
\end{tabular}

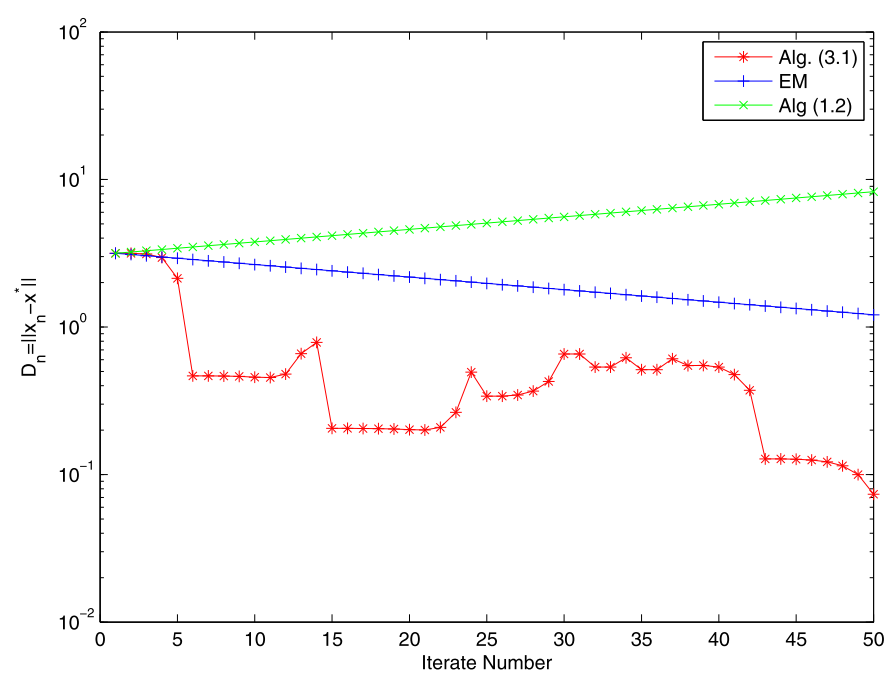

Figure 1 Numerical results as regards Example 2

Example 2 Let $H=\mathbb{R}^{m}$. We consider a classical problem $[23,24]$. The feasible set is $C=\mathbb{R}^{m}$ and $F: \mathbb{R}^{m} \rightarrow \mathbb{R}^{m}$ is a linear operator in the form

$$
F(x):=A x
$$

for each $x \in \mathbb{R}^{m}$, where $A=\left(a_{i, j}\right)_{1 \leq i, j \leq m}$ is a matrix in $\mathbb{R}^{m \times m}$ whose terms are given by

$$
a_{i, j}= \begin{cases}-1, & \text { if } j=m+1-i \text { and } j>i \\ 1, & \text { if } j=m+1-i \text { and } j<i \\ 0, & \text { otherwise }\end{cases}
$$

Then $F$ is monotone and $\|A\|$-Lipschitz continuous. This is a classical example of a problem where the usual gradient method does not converge. We can easily see that $V I(C, F)=$ $F^{-1}(0)$ and the zero vector is the unique element in $V I(C, F)$. We denote $x^{*}=(0,0, \ldots, 0)^{T}$. Choose $x_{1}=(1,1, \ldots, 1)^{T}$ and $\lambda_{n}=\lambda=0.2 /\|A\|$ in each iterative scheme. Take $x_{0}=$ $(2,2, \ldots, 2)^{T}, \alpha_{n}=2$, and $\gamma=1$ in our iterative scheme (3.1). We show the numerical results for the cases $m=10,20,30,40$ respectively in Fig. 1, Fig. 2, Fig. 3, and Fig. 4. 


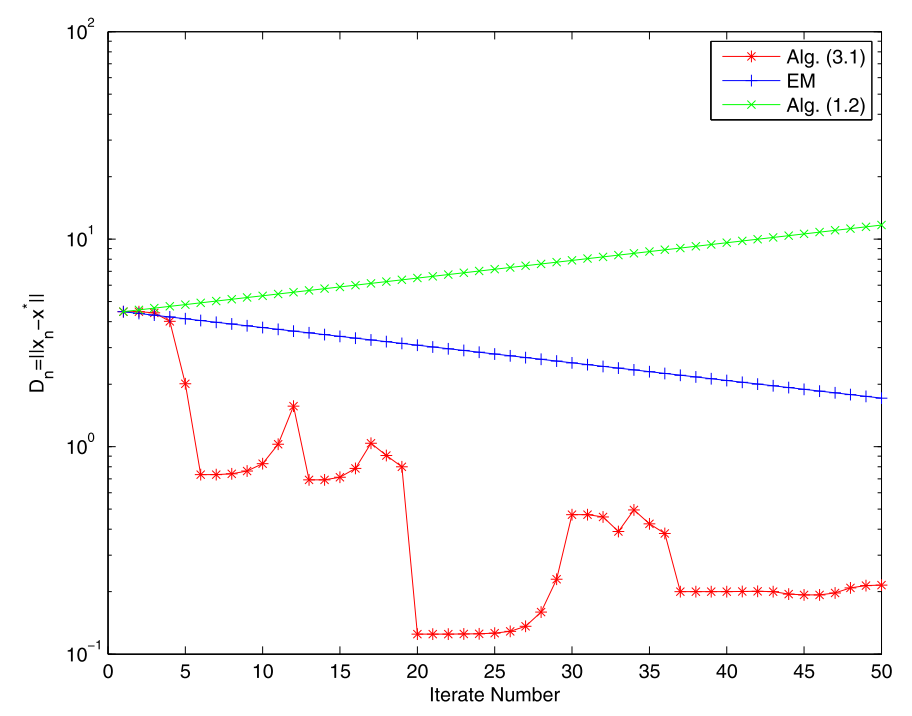

Figure 2 Numerical results as regards Example 2

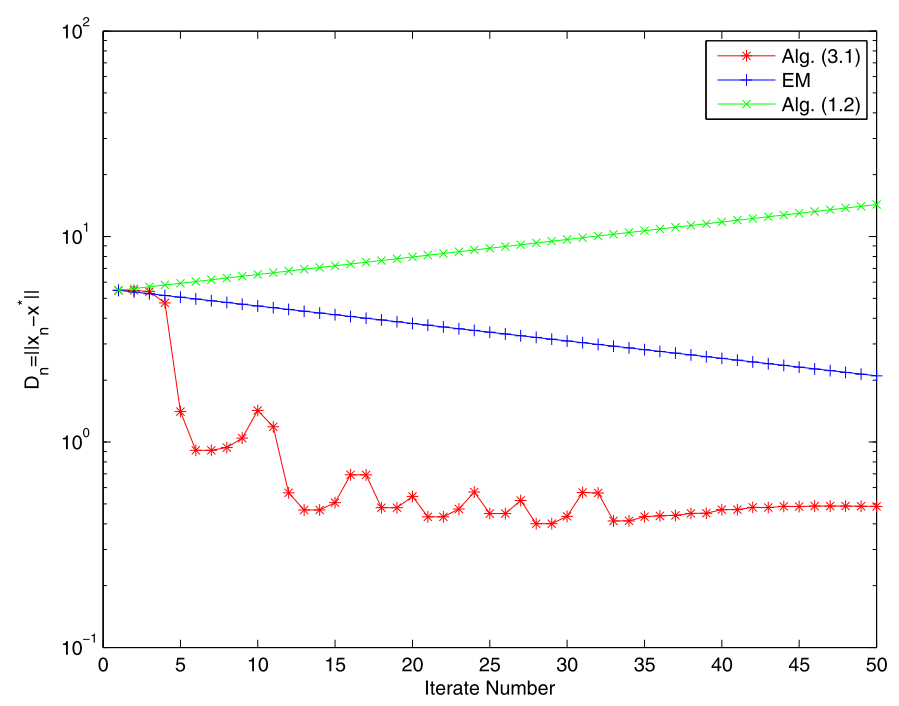

Figure 3 Numerical results as regards Example 2

\section{Conclusion}

For a variational inequality problem, Algorithms (1.2) and (1.3) have been studied. Considering that sometimes the conditions of operators are not strong enough, He proposed the projection and contraction algorithm. In 2017, Dong et al. proposed the inertial projection and contraction algorithm originated from the second-order dynamical systems. Recently, Dong et al. proposed a strong convergence method for solving zero point problems by using hybrid method. Motivated by their work, we propose an inertial hybrid algorithm for solving variational inequality problems in Hilbert spaces and obtain strong convergence theorems. 


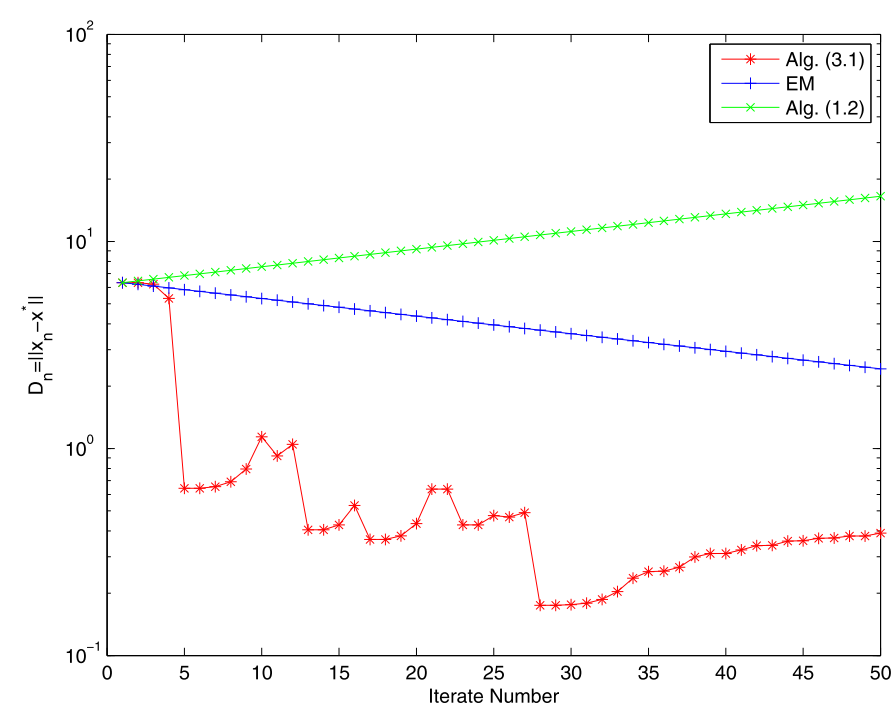

Figure 4 Numerical results as regards Example 2

\section{Funding}

This work was supported by Tianjin Key Lab for Advanced Signal Processing, Civil Aviation University of China [grant number 2019 ASP-TJ02].

\section{Availability of data and materials}

Not applicable.

\section{Competing interests}

The authors declare that they have no competing interests.

\section{Authors' contributions}

All the authors read and approved the final manuscript.

\section{Publisher's Note}

Springer Nature remains neutral with regard to jurisdictional claims in published maps and institutional affiliations.

\section{Received: 3 September 2019 Accepted: 13 January 2020 Published online: 16 January 2020}

\section{References}

1. Fichera, G.: Sul problema elastostatico di Signorini con ambigue condizioni al contorno. Atti Accad. Naz. Lincci, VIII. Scr., Rend., Cl. Sci. Fis. Mat. Nat. 34, 138-142 (1963)

2. Fichera, G.: Problemi elastostatici con vincoli unilaterali: il problema di Signorini con ambigue condizioni al contorno. Atti Accad. Naz. Lincci, Mem., Cl. Sci. Fis. Mat. Nat., Sez. 7, 91-140 (1964)

3. Stampacchia, G.: Formes bilineaires coercitives sur les ensembles convexes. C. R. Math. Acad. Sci. Paris 258, 4413-4416 (1964)

4. Xu, H.K.: Averaged mappings and the gradient-projection algorithm. J. Optim. Theory Appl. 150, 360-378 (2011)

5. Korpelevich, G.M.: An extragradient method for finding saddle points and for other problems. Ėkon. Mat. Metody 12, 747-756 (1976)

6. Censor, Y., Gibali, A., Reich, S.: Extensions of Korpelevich's extragradient method for the variational inequality problem in Euclidean space. Optimization 61(9), 1119-1132 (2012)

7. He, B.S.: A class of projection and contraction methods for monotone variational inequalities. Appl. Math. Optim. 35, 69-76 (1997)

8. Dong, Q.L., Cho, Y.J., Zhong, L.L., Rassias, T.M.: Inertial projection and contraction algorithms for variational inequalites. J. Glob. Optim. 70, 687-704 (2018)

9. Dong, Q.L., Jiang, D., Cholamjiak, P., Shehu, Y.: A strong convergence result involving an inertial forward-backward algorithm for monotone inclusions. J. Fixed Point Theory Appl. 19(4), 3097-3118 (2017)

10. Xu, H.K.: Iterative methods for the split feasibility problem in infinite-dimensional Hilbert space. Inverse Probl. 26, $10518(2010)$

11. Tian, M., Jiang, B.N.: Weak convergence theorem for a class of split variational inequality problems and applications in a Hilbert space. J. Inequal. Appl. 2017, 123 (2017)

12. Goebel, K., Reich, S.: Uniform Convexity, Hyperbolic Geometry, and Nonexpansive Mappings. Marcel Dekker, New York (1984)

13. Baillon, J.-B., Bruck, R.E., Reich, S.: On the asymptotic behavior of nonexpansive mappings and semigroups in Banach spaces. Houst. J. Math. 4, 1-9 (1978) 
14. Ceng, L.C., Ansari, Q.H., Yao, J.C.: Some iterative methods for finding fixed points and for solving constrained convex minimization problems. Nonlinear Anal. 74, 5286-5302 (2011)

15. Takahashi, W., Toyoda, M.: Weak convergence theorem for nonexpansive mappings and monotone mappings. J. Optim. Theory Appl. 118, 417-428 (2003)

16. Kopecká, E., Reich, S.: A note on alternating projections in Hilbert space. J. Fixed Point Theory Appl. 12, 41-47 (2012)

17. Takahashi, W., Xu, H.K., Yao, J.C.: Iterative methods for generalized split feasibility problems in Hilbert spaces. Set-Valued Var. Anal. 23(2), 205-221 (2015)

18. Tian, M., Jiao, S.W., Liou, Y.C.: Methods for solving constrained convex minimization problems and finding zeros of the sum of two operators in Hilbert spaces. J. Inequal. Appl. 2015, 227 (2015)

19. Takahashi, W., Nadezhkina, N.: Weak convergence theorem by an extragradient method for nonexpansive mappings and monotone mappings. J. Optim. Theory Appl. 128, 191-201 (2006)

20. Tian, M., Jiang, B.N.: Weak convergence theorem for variational inequality problems with monotone mapping in Hilbert space. J. Inequal. Appl. 2016, 286 (2016)

21. Censor, Y., Elfving, T:: A multiprojection algorithm using Bregman projections in a product space. Numer. Algorithms 8, 221-239 (1994)

22. Byrne, $\mathrm{C}: \mathrm{A}$ unified treatment of some iterative algorithms in signal processing and image reconstruction. Inverse Probl. 20, 103-120 (2004)

23. Malitsky, Yu.V.: Projected reflected gradient methods for variational inequalities. SIAM J. Optim. 25(1), 502-520 (2015)

24. Yang, J., Liu, H.: A modified projected gradient method for monotone variational inequalities. J. Optim. Theory Appl. 179, 197-211 (2018)

\section{Submit your manuscript to a SpringerOpen ${ }^{\circ}$ journal and benefit from:}

- Convenient online submission

- Rigorous peer review

- Open access: articles freely available online

- High visibility within the field

- Retaining the copyright to your article

Submit your next manuscript at $\boldsymbol{~ s p r i n g e r o p e n . c o m ~}$ 